\title{
Stability of azasetron-dexamethasone mixture for chemotherapy- induced nausea and vomiting administration
}

\author{
Bao-Xia Fang ${ }^{1, *}$, Fu-Chao Chen ${ }^{1, *}$, Dan Zhu², Jun Guo ${ }^{3}$ and Lin-Hai Wang ${ }^{2}$ \\ ${ }^{1}$ Department of Pharmacy, Dongfeng Hospital, Hubei University of Medicine, Shiyan, Hubei 442008, P.R. China \\ ${ }^{2}$ Department of Pharmacy, Renmin Hospital, Hubei University of Medicine, Shiyan, Hubei 442000, P.R. China \\ ${ }^{3}$ Department of Oncology, Dongfeng Hospital, Hubei University of Medicine, Shiyan, Hubei 442008, P.R. China \\ *These authors contributed equally to this work \\ Correspondence to: Lin-Hai Wang, email: wanglhpharmacy@sina.com \\ Keywords: chemotherapy-induced nausea and vomiting; antiemetic; dexamethasone; azasetron; drug stability \\ Received: May 30, $2017 \quad$ Accepted: October 13, $2017 \quad$ Published: October 31, 2017 \\ Copyright: Fang et al. This is an open-access article distributed under the terms of the Creative Commons Attribution License 3.0 \\ (CC BY 3.0), which permits unrestricted use, distribution, and reproduction in any medium, provided the original author and source \\ are credited.
}

\section{ABSTRACT}

Combination antiemetic therapy has become common practice for the prevention of nausea and vomiting caused by anticancer drugs. In this study, we investigated the stability of azasetron hydrochloride $0.1 \mathrm{mg} / \mathrm{mL}$ plus dexamethasone sodium phosphate $0.05,0.1$, or $0.2 \mathrm{mg} / \mathrm{mL}$ in $0.9 \%$ sodium chloride injection and stored in polyolefin bags and glass bottles over a period of 14 days at $4^{\circ} \mathrm{C}$ and 48 hours at $25^{\circ} \mathrm{C}$. The stability studies were evaluated by visual inspection, $\mathrm{pH}$ measurement, and a high-pressure liquid chromatography assay of drug concentrations. During the study period, the concentration of each drug in the various solutions remained above $97 \%$ of the initial concentration at both $4^{\circ} \mathrm{C}$ and $25^{\circ} \mathrm{C}$ when protected from room light. Under the condition of $25^{\circ} \mathrm{C}$ with exposure to room light, the concentrations of both drugs were significantly lowered over 48 hours. The pH value decreased, and the color changed from colorless to pink. Our study demonstrates that the azasetrondexamethasone mixture at a clinically relevant concentration seems to be stable for 48 hours at $25^{\circ} \mathrm{C}$ and for 14 days at $4^{\circ} \mathrm{C}$ when packaged in polyolefin bags or glass bottles and protected from room light. The room light is the main influential factor on stability. Clinicians should be aware that combinations of azasetron hydrochloride and dexamethasone sodium phosphate in solution with light exposure should be avoided.

\section{INTRODUCTION}

Chemotherapy-induced nausea and vomiting (CINV) are common side effects of many antineoplastic regimens in the treatment of cancer and can last for days following therapy, result in various metabolic and nutritional status, and sometimes even discontinue or postpone patients' chemotherapy [1-3]. Currently, adherence to antiemetic guidelines provides effective relief from CINV, and patients rapidly return to normal daily activities after treatment [4-6]. According to antiemetic guidelines, combination antiemetic therapy has become common practice for the prevention of CINV, and the effectiveness of the type 3 serotonin receptor antagonists
(5-HT $\left.\mathrm{H}_{3} \mathrm{RA}\right)$ has been enhanced by combination with dexamethasone [1, 7-9].

Azasetron, a selective potent $5-\mathrm{HT}_{3} \mathrm{RA}$, is a derivative of benzamide with a different chemical structure from other 5- $\mathrm{HT}_{3} \mathrm{RA}$, such as ondansetron, granisetron, tropisetron, and ramosetron, and has a longer duration of action and a higher affinity for the 5- $\mathrm{HT}_{3}$ receptor [10]. Azasetron was first approved in 1994 by the Yoshitomi Pharm, Ind., Ltd. and Japan Tobacco Inc and is gaining popularity in Asia Pacific countries as an antiemetic for the prevention of CINV and postoperative nausea and vomiting [11-15]. Dexamethasone, a synthetic corticosteroid, has long been used as an antiemetic agent in patients undergoing cancer chemotherapy $[16,17]$, 
being effective for both acute and delayed nausea and vomiting. A survey of the literature revealed that coadministration of azasetron with dexamethasone was more effective in reducing CINV compared to azasetron alone in patients undergoing cisplatin chemotherapy $[14,15]$. Currently, there are no commercially available antiemetic combination mixtures, and they must be prepared in the hospital pharmacy intravenous admixture service for clinical use. Known incompatibilities, such as color change, $\mathrm{pH}$ shifts, precipitation, particle formation, gas evolution, and crystallization during i.v. administration arising from the combination of therapies can exist [18]. Hence, knowledge of the compatibility and stability of this drug combination is important.

From the literature survey, several studies have assessed the stability and compatibility of dexamethasone combines with 5- $\mathrm{HT}_{3} \mathrm{RA}$, such as ondansetron, granisetron, tropisetron, or palonosetron hydrochloride in binary admixtures [19-27]. The stability of azasetron with dexamethasone in solution for CINV administration has not been reported. Thus, the aim of this study was to determine the stability of the two drugs, at 3 different concentration combinations, prepared in $0.9 \%$ sodium chloride injection and stored in 2 different types of containers (glass bottles and polyolefin bags) for a period of 14 days at $4^{\circ} \mathrm{C}$ protected from room light and 48 hours at $25^{\circ} \mathrm{C}$ protected from room light or exposure to room light.

\section{RESULTS}

\section{Physical compatibility}

During the stability study period, no precipitate was visible in any solution, no color changes occurred, no gas was produced, and the $\mathrm{pH}$ values remained stable at both $4^{\circ} \mathrm{C}$ and $25^{\circ} \mathrm{C}$ when protected from room light. In contrast, when stored at $25^{\circ} \mathrm{C}$ and exposed to room light, the $\mathrm{pH}$ value of the infusion mixtures decreased, and the color changed from colorless to pink. The results of the $\mathrm{pH}$ value for azasetrondexamethasone mixtures in polyolefin bags and glass bottles at $25^{\circ} \mathrm{C}$ and exposed to room light are presented in Table 1. As indicated in Table 1, all drug mixtures were nearly neutral with $\mathrm{pH}$ values ranging from $6.8-7.2$ at the start of the study as a consequence of increasing dexamethasone sodium phosphate concentrations in the mixtures. The $\mathrm{pH}$ changes were 0.9-1.2 units of the initial $\mathrm{pH}$ for all drug mixtures at $25^{\circ} \mathrm{C}$ with exposure to room light. The color changes of the infusion mixtures at $25^{\circ} \mathrm{C}$ and exposed to room light are illustrated in Figure 1. From Figure 1 we can see that all the mixtures were clear, colorless at the beginning. After 4 hours, the presence of a canary yellow was observed. At the end of the study (48 hours), the color changed from yellow to pink when stored at $25^{\circ} \mathrm{C}$ with light exposure.

\section{Chemical stability study of azasetron and dexamethasone at $4^{\circ} \mathrm{C}$}

The results of the chemical stability study for the admixtures of azasetron and dexamethasone in polyolefin bags and glass bottles when stored at $4^{\circ} \mathrm{C}$ over 14 days and protected from room light are summarized in Table 2. As shown in Table 2, losses of dexamethasone sodium phosphate and azasetron hydrochloride were less than $3 \%$ in 3 different concentration combinations stored in polyolefin bags and glass bottles over a period of 14 days at $4^{\circ} \mathrm{C}$ and protected from room light.

\section{Chemical stability study of azasetron and dexamethasone at $25^{\circ} \mathrm{C}$}

At room temperature, solutions of dexamethasone sodium phosphate $(0.05,0.1$, or $0.2 \mathrm{mg} / \mathrm{mL})$ combined with azasetron hydrochloride $(0.1 \mathrm{mg} / \mathrm{mL})$ were also stable for 48 hours when packaged in polyolefin bags or glass bottles and protected from room light (Figures 2, 3). Under the condition of light exposure, the concentrations of both drugs were significantly lowered over 48 hours. Figures 2, 3 show the variation in the remaining concentrations of azasetron hydrochloride and dexamethasone sodium phosphate in polyolefin bags or glass bottles that were exposed to room light during the time of the study; as can be observed, remaining concentrations of azasetron hydrochloride were lower than $50 \%$ after 4 hours of storage. After 24 hours, losses of azasetron hydrochloride and dexamethasone sodium phosphate were more than $70 \%$ and $10 \%$, respectively. At the end of the study (48 hours), losses of azasetron hydrochloride and dexamethasone sodium phosphate were more than $80 \%$ and $20 \%$ in both polyolefin bags and glass bottles.

\section{DISCUSSION}

CINV is one of the most debilitating adverse events of chemotherapy in cancer patients. Several neurotransmitters, including dopamine, serotonin, and substance $\mathrm{P}$, have been identified as important mediators of CINV [1, 2]. Hence, many treatment guidelines recommend that co-administration of antiemetics from different classes could be a more effective antiemetic treatment modality, and dexamethasone is a standard component of antiemetic combination regimens with 5- $\mathrm{HT}_{3}$ antagonists [6-8, 28, 29]. Fujii $\mathrm{M}$ et al [14] found that azasetron combined with dexamethasone was more effective than azasetron alone for prevention of cisplatin-induced emesis in patients with advanced head and neck carcinoma. Lee et al have administered azasetron combined with dexamethasone and 
Table 1: pH values of azasetron-dexamethasone mixtures based on three different concentrations packaged in polyolefin bags or glass bottles and exposed to room light at $25^{\circ} \mathrm{C}$ over 48 hours

\begin{tabular}{lccccc}
\hline Mixture and & \multicolumn{5}{c}{$\mathbf{p H}$ value $(\mathbf{m e a n} \pm \mathbf{S D} ; \boldsymbol{n}=\mathbf{3})$} \\
\cline { 2 - 6 } Container & 0 hours & 4 hours & $\mathbf{8}$ hours & 24 hours & 48 hours \\
\hline Glass bottles & & & & \\
AD5 & $6.89 \pm 0.08$ & $6.32 \pm 0.06$ & $6.16 \pm 0.04$ & $6.03 \pm 0.05$ & $5.84 \pm 0.04$ \\
AD10 & $7.00 \pm 0.04$ & $6.44 \pm 0.09$ & $6.11 \pm 0.05$ & $5.95 \pm 0.03$ & $5.82 \pm 0.09$ \\
AD20 & $7.24 \pm 0.06$ & $6.65 \pm 0.04$ & $6.38 \pm 0.07$ & $6.14 \pm 0.04$ & $6.08 \pm 0.06$ \\
Polyolefin bags & & & & \\
AD5 & $6.80 \pm 0.06$ & $6.47 \pm 0.09$ & $6.13 \pm 0.05$ & $6.02 \pm 0.03$ & $5.90 \pm 0.04$ \\
AD10 & $7.03 \pm 0.07$ & $6.55 \pm 0.08$ & $6.27 \pm 0.04$ & $6.10 \pm 0.05$ & $5.98 \pm 0.02$ \\
AD20 & $7.19 \pm 0.04$ & $6.81 \pm 0.05$ & $6.56 \pm 0.05$ & $6.35 \pm 0.06$ & $6.14 \pm 0.03$ \\
\hline
\end{tabular}

combinations of ondansetron and dexamethasone in the prevention of delayed CINV and have found that azasetron showed inferiority in the control of delayed CINV compared with ondansetron [15].

In everyday clinical practice, co-administration of antiemetic drugs in the same intravenous infusion solution is often highly preferred to improve the management of ambulatory procedures, time management and the number of administered intravenous preparations [22]. All this would improve patient safety and comfort. To our knowledge, no published information is available on the compatibility and stability of dexamethasone in combination with azasetron in infusion solution. The aim of this study was to address this lack of information.

To date, there is limited published information concerning the compatibility and stability of azasetron
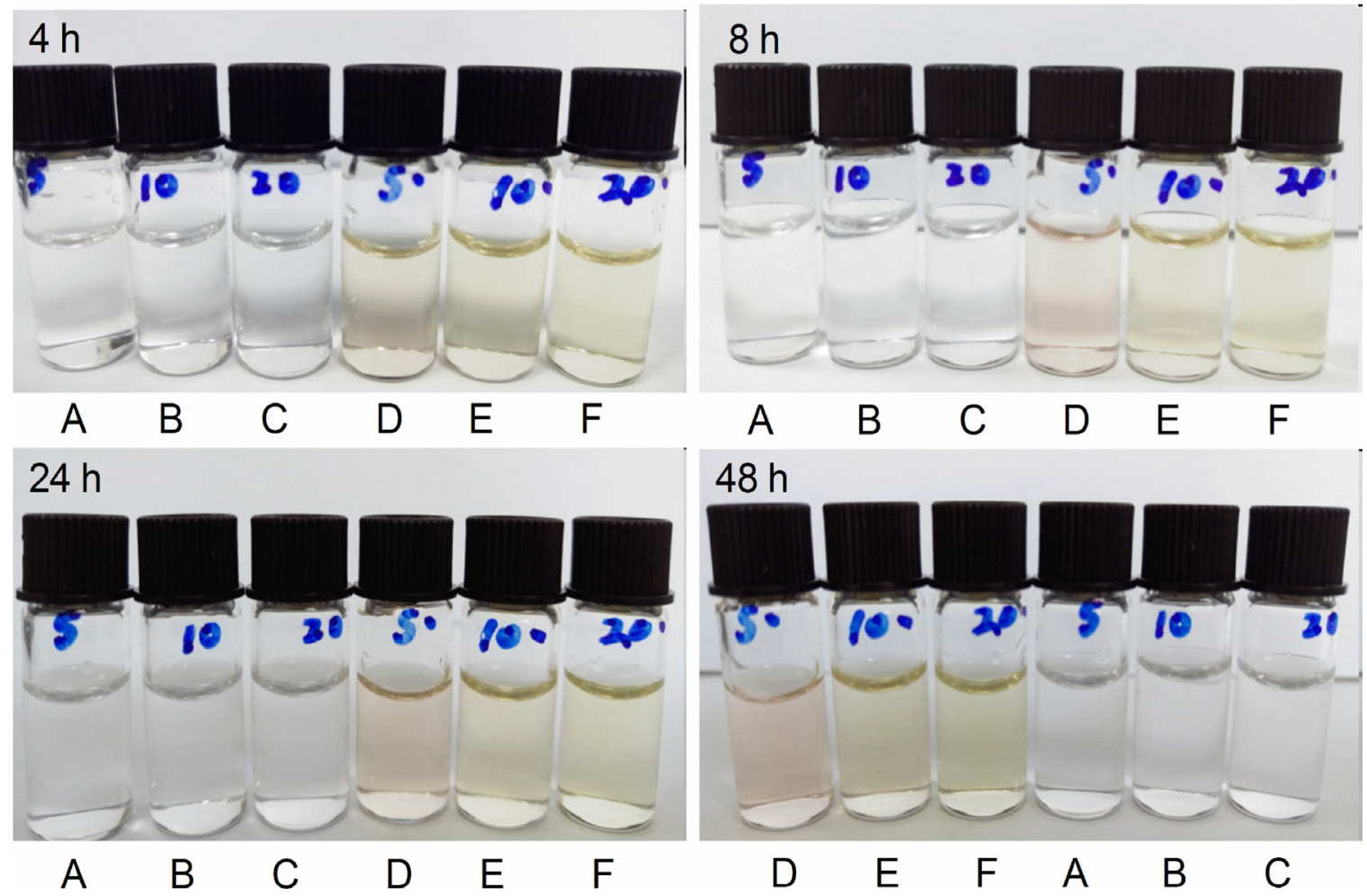

$\begin{array}{llllll}D & E & F & A & B & C\end{array}$

Figure 1: The color changes of the azasetron-dexamethasone mixtures at $4 \mathrm{hr}, 8 \mathrm{hr}, 24 \mathrm{hr}$ and $48 \mathrm{hr}$ after preparation. (A) $\mathrm{AD} 5\left(25^{\circ} \mathrm{C}\right.$, protected from room light); (B) $\mathrm{AD} 10\left(25^{\circ} \mathrm{C}\right.$, protected from light); (C) $\mathrm{AD} 20\left(25^{\circ} \mathrm{C}\right.$, protected from room light); (D) $\mathrm{AD} 5\left(25^{\circ} \mathrm{C}\right.$, exposed to room light); (E) AD10 $\left(25^{\circ} \mathrm{C}\right.$, exposed to room light); (F) $\mathrm{AD} 20\left(25^{\circ} \mathrm{C}\right.$, exposed to room light). AD5: azasetron hydrochloride $0.1 \mathrm{mg} / \mathrm{mL}$ plus dexamethasone sodium phosphate $0.05 \mathrm{mg} / \mathrm{mL}$ in $0.9 \%$ sodium chloride injection; AD10: azasetron hydrochloride $0.1 \mathrm{mg} / \mathrm{mL}$ plus dexamethasone sodium phosphate $0.1 \mathrm{mg} / \mathrm{mL}$ in $0.9 \%$ sodium chloride injection; AD20: azasetron hydrochloride $0.1 \mathrm{mg} / \mathrm{mL}$ plus dexamethasone sodium phosphate $0.2 \mathrm{mg} / \mathrm{mL}$ in $0.9 \%$ sodium chloride injection. 
Table 2: Stability of azasetron-dexamethasone mixtures based on three different concentrations packaged in polyolefin bags or glass bottles, and protected from room light over 14 days at $4^{\circ} \mathrm{C}$

\begin{tabular}{|c|c|c|c|c|c|c|}
\hline \multirow{2}{*}{$\begin{array}{l}\text { Mixture and } \\
\text { Container }\end{array}$} & \multirow{2}{*}{ Drug } & \multicolumn{5}{|c|}{ Initial Concentration Remaining (Mean \pm S.D. $\% ; n=3)$} \\
\hline & & Day 1 & Day 3 & Day 7 & Day 10 & Day 14 \\
\hline \multicolumn{7}{|l|}{ Glass bottles } \\
\hline \multirow[t]{2}{*}{ AD5 } & azasetron & $100.63 \pm 0.2$ & $99.93 \pm 0.1$ & $99.35 \pm 0.3$ & $99.78 \pm 0.2$ & $98.19 \pm 0.4$ \\
\hline & dexamethasone & $100.84 \pm 0.3$ & $100.39 \pm 0.2$ & $100.73 \pm 0.4$ & $99.04 \pm 0.5$ & $99.62 \pm 0.3$ \\
\hline \multirow[t]{2}{*}{$\mathrm{AD} 10$} & azasetron & $100.53 \pm 0.3$ & $100.55 \pm 0.2$ & $100.84 \pm 0.4$ & $100.74 \pm 0.4$ & $99.95 \pm 0.2$ \\
\hline & dexamethasone & $99.28 \pm 0.5$ & $99.37 \pm 0.2$ & $99.81 \pm 0.6$ & $100.73 \pm 0.4$ & $100.91 \pm 0.2$ \\
\hline \multirow[t]{2}{*}{ AD20 } & azasetron & $100.63 \pm 0.2$ & $100.94 \pm 0.2$ & $100.73 \pm 0.3$ & $100.85 \pm 0.5$ & $98.05 \pm 0.6$ \\
\hline & dexamethasone & $99.36 \pm 0.1$ & $99.80 \pm 0.2$ & $99.05 \pm 0.2$ & $99.15 \pm 0.2$ & $99.63 \pm 0.3$ \\
\hline \multicolumn{7}{|c|}{ Polyolefin bags } \\
\hline \multirow[t]{2}{*}{ AD5 } & azasetron & $100.96 \pm 0.2$ & $101.04 \pm 0.1$ & $101.47 \pm 0.3$ & $100.96 \pm 0.2$ & $99.54 \pm 0.2$ \\
\hline & dexamethasone & $99.71 \pm 0.1$ & $99.92 \pm 0.2$ & $99.99 \pm 0.2$ & $100.06 \pm 0.4$ & $99.53 \pm 0.2$ \\
\hline \multirow[t]{2}{*}{ AD10 } & azasetron & $100.90 \pm 0.4$ & $100.69 \pm 0.2$ & $100.41 \pm 0.2$ & $100.44 \pm 0.5$ & $100.67 \pm 0.2$ \\
\hline & dexamethasone & $99.66 \pm 0.5$ & $99.58 \pm 0.2$ & $99.49 \pm 0.3$ & $99.60 \pm 0.3$ & $99.60 \pm 0.5$ \\
\hline \multirow[t]{2}{*}{ AD20 } & azasetron & $100.89 \pm 0.2$ & $100.27 \pm 0.2$ & $100.2 \pm 0.1$ & $100.04 \pm 0.4$ & $97.85 \pm 0.2$ \\
\hline & dexamethasone & $99.87 \pm 0.1$ & $99.90 \pm 0.3$ & $99.76 \pm 0.2$ & $99.99 \pm 0.2$ & $99.19 \pm 0.5$ \\
\hline
\end{tabular}

hydrochloride, either singly or combined with other drugs in infusion solutions. Wang DW et al [30] studied the effect of light and temperature on the stability of azasetron hydrochloride prepared in $0.9 \%$ sodium chloride solutions or $5 \%$ glucose injection. They reported that azasetron hydrochloride was stable for $24 \mathrm{~h}$ when stored at $4^{\circ} \mathrm{C}, 25^{\circ} \mathrm{C}$ or $35^{\circ} \mathrm{C}$ with protection from room light. The concentration of azasetron was significantly lost in normal saline and glucose injection $4 \mathrm{~h}$ after mixture, and the color changed from colorless to pink when stored at $25^{\circ} \mathrm{C}$ or $35^{\circ} \mathrm{C}$ with light exposure. In the present study, all azasetron-dexamethasone admixtures showed similar results in normal saline with light exposure. Our study identified that room light is an important factor that affects the mixture's stability, and therefore, all dexamethasone-azasetron admixtures prepared for clinical use should be protected from room light to avoid this destabilizing factor.

Regarding dexamethasone, the stability and compatibility of dexamethasone sodium phosphate, either singly or combined with other drugs in infusion solutions, have been widely tested and studied. Dexamethasone sodium phosphate degradation was less than $3 \%$ when diluted in $0.9 \%$ sodium chloride injection and stored in polypropylene syringes for 22 days at $25^{\circ} \mathrm{C}$ [31]. The combination of dexamethasone sodium phosphate with certain drugs in infusion solutions has displayed variable results. It has been proven to be stable with ketamine hydrochloride, metoclopramide hydrochloride, granisetron hydrochloride, ondansetron hydrochloride, palonosetron hydrochloride, tramadol hydrochloride, diphenhydramine hydrochloride, lorazepam, and cefpirome sulfate, among others [19-26, 32-37], whereas it precipitates at certain concentrations when combined in solution with morphine hydrochloride, hydromorphone hydrochloride, midazolam hydrochloride, haloperidol lactate, propofol, or fenoldopam mesylate [38-43].

In this stability study, we have examined only physicochemical stability without considering microbial contamination. In clinical practice, we should follow the United States Pharmacopeia and National Formulary (USP/NF) Chapter 797 [44]. Under this regulation, the preparation is categorized as a low-risk compounding sterile product [45]. To ensure its safety, the preparation should be used by 48 hours beyond the date at room temperature or by 14 days beyond the date at refrigerated temperatures, based on USP specifications. The results of our stability studies show that infusion solutions containing concentrations of azasetron hydrochloride $0.1 \mathrm{mg} / \mathrm{ml}$ combined with dexamethasone sodium phosphate $(0.05-0.2 \mathrm{mg} / \mathrm{ml})$ were very stable for 48 hours at $25^{\circ} \mathrm{C}$ and for 14 days at $4^{\circ} \mathrm{C}$ when packaged in polyolefin bags or glass bottles and protected from room light. Clinicians should be aware that there may be significant loss of azasetron and dexamethasone with light exposure. Based on this finding, it is recommended that, whenever possible, combinations of azasetron and dexamethasone in solution with light exposure should be avoided. 

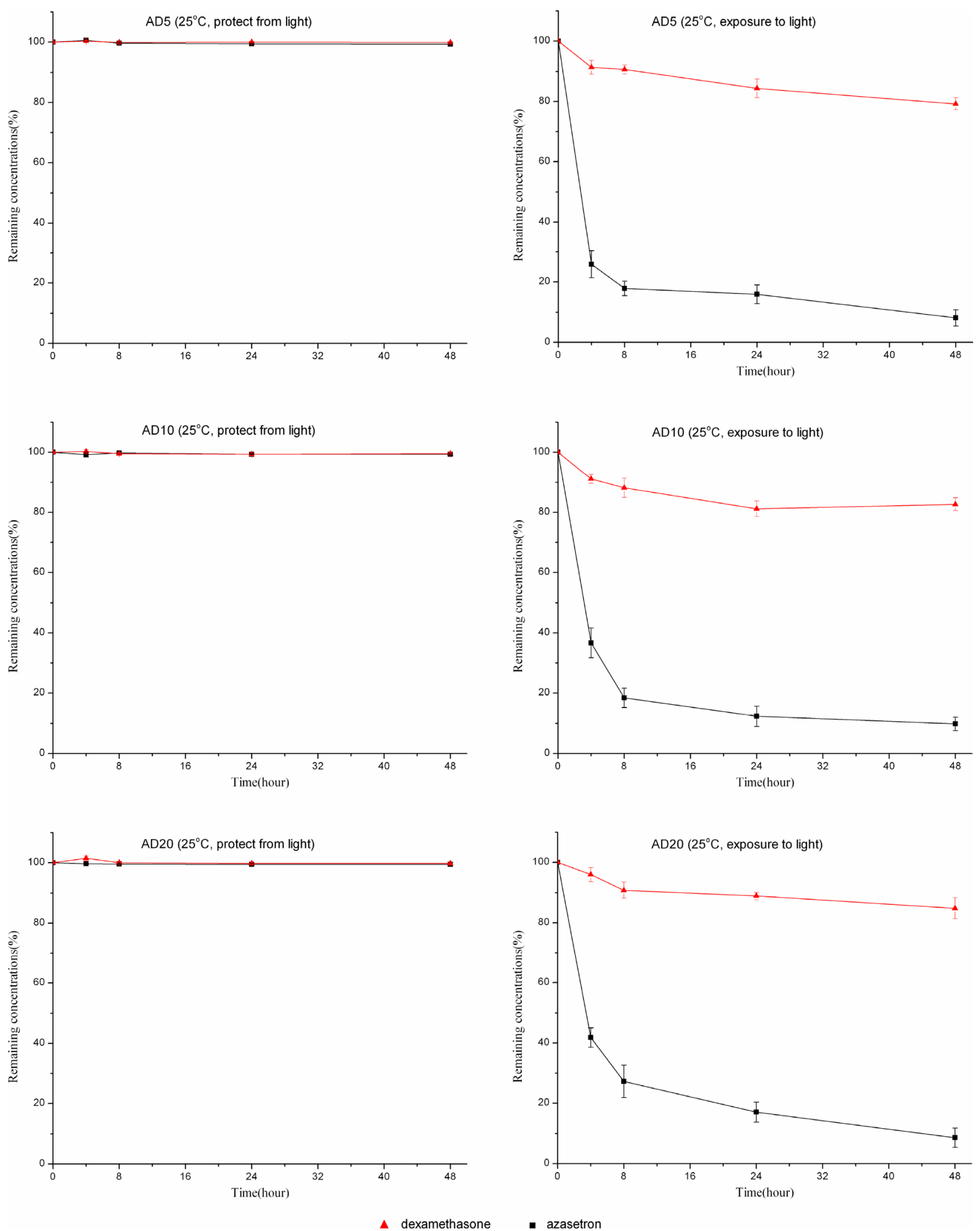

- azasetron

Figure 2: The stability of azasetron-dexamethasone mixtures based on three different concentrations packaged in glass bottles and stored at $25^{\circ} \mathrm{C}$, under light exposure or light protection conditions, for $\mathbf{4 8}$ hours. Error bars represent the standard deviation $(n=3)$. 

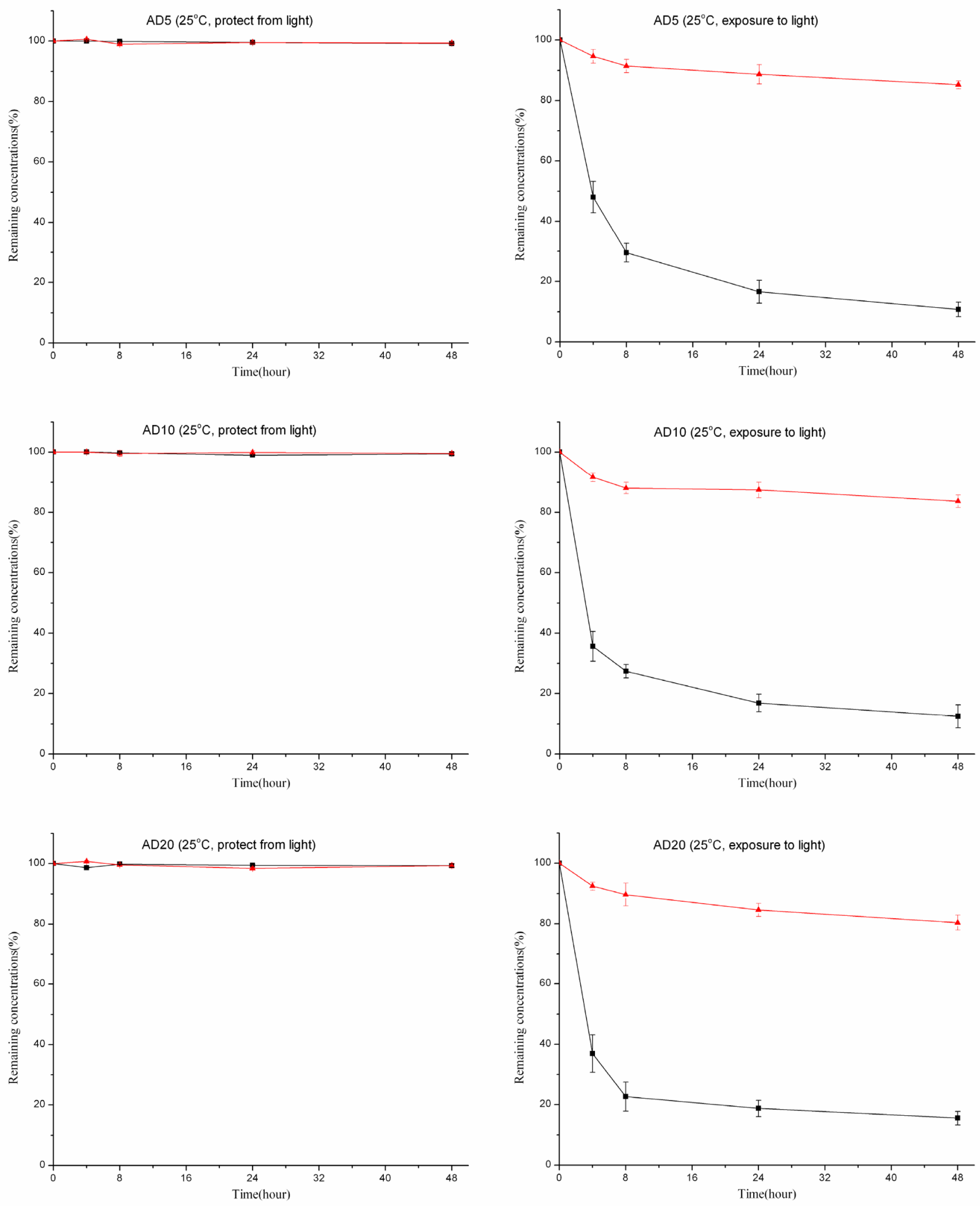

A dexamethasone

- azasetron

Figure 3: The stability of azasetron-dexamethasone mixtures based on three different concentrations packaged in polyolefin bags and stored at $25^{\circ} \mathrm{C}$, under light exposure or light protection conditions, for 48 hours. Error bars represent the standard deviation $(n=3)$. 


\section{MATERIALS AND METHODS}

\section{Chemicals and reagents}

The working standards of dexamethasone sodium phosphate $(99.8 \%$, HPLC-grade) and azasetron hydrochloride (99.7\%, HPLC-grade) were purchased from the National Institutes for Food and Drug Control (Beijing, China). The pharmaceutical formulations used in this study were dexamethasone sodium phosphate injection $5 \mathrm{mg} / 1$ $\mathrm{mL}$ (Cisen Pharmaceutical Co., Ltd., Shandong, China) and azasetron hydrochloride injection $10 \mathrm{mg} / 2 \mathrm{~mL}$ (Zhejiang Wanma pharmaceutical Co., Ltd., Hangzhou, China). The solution of $0.9 \%$ sodium chloride injection used to prepare the sample mixtures was from Kelun Pharmaceutical Co., Ltd. (Sichuang, China).

\section{Analytical method}

The concentrations of azasetron hydrochloride and dexamethasone sodium phosphate were determined using a previously described high performance liquid chromatography (HPLC) method [27]. Chromatography equipment included a Shimadzu LC-20A (Shimadzu, Kyoto, Japan) LC system composed of a LC-20AD quaternary pump, a DGU-20A5 degasser unit, a SIL-20AC auto-injector, a CTO-20A column oven and a SPD-M20A diode array detector (DAD). Data acquisition was carried out using Class VP 7.4 software (Shimadzu, Kyoto, Japan). Dexamethasone sodium phosphate was separated from azasetron hydrochloride by HPLC on a phenomenex $\mathrm{C}_{18}$ column $(4.6 \mathrm{~mm} \times 150 \mathrm{~mm}, 5 \mu \mathrm{m})$ with mobile phase of acetonitrile, $50 \mathrm{mM} \mathrm{KH}_{2} \mathrm{PO}_{4}$ buffer, and triethylamine $(25: 74: 1 ; \mathrm{v} / \mathrm{v})$. The $\mathrm{pH}$ was adjusted to 4.0 with $85 \%$ phosphoric acid. Flow rate was $1.0 \mathrm{~mL} / \mathrm{min}$, and the detection wavelengths for dexamethasone and azasetron were $241 \mathrm{~nm}$ and $302 \mathrm{~nm}$, respectively. The assay was performed at $30^{\circ} \mathrm{C}$ and the injection volume was $20 \mu \mathrm{L}$. The degraded solution of azasetron hydrochloride or dexamethasone sodium phosphate was used to prove the specificity of the HPLC method. This solution was incubated in $1 \mathrm{~N}$ hydrochloric acid, $1 \mathrm{~N}$ sodium hydroxide, $3 \%$ hydrogen peroxide for 5 hours at $60^{\circ} \mathrm{C}$. The chromatogram of each admixture showed retention times of $4.5 \mathrm{~min}$ and $10.7 \mathrm{~min}$ for azasetron and dexamethasone, respectively. Degradation peaks were detected which did not interfere with the corresponding drug.

\section{Preparation of dexamethasone-azasetron solutions}

To mimic a concentration range relevant to clinical practice and the conditions commonly occurring in hospitals [14-17], 3 different concentration combinations were freshly prepared under aseptic conditions in laminar flow hoods, kept in the dark under refrigeration $(4 \pm$ $0.5^{\circ} \mathrm{C}$ ) for 14 days and protected from room light or exposed to room light at room temperature $\left(25 \pm 0.5^{\circ} \mathrm{C}\right)$ for 48 hours.

Solution 1 (AD5): $1 \mathrm{~mL}(5 \mathrm{mg})$ dexamethasone sodium phosphate injectable solution and $2 \mathrm{~mL}(10 \mathrm{mg})$ azasetron hydrochloride injectable solution were transferred to $100 \mathrm{~mL}$ polyolefin bags or glass bottles and filled with $0.9 \%$ sodium chloride injection.

Solution 2 (AD10): $2 \mathrm{~mL}(10 \mathrm{mg}$ ) dexamethasone sodium phosphate injectable solution and $2 \mathrm{~mL}(10 \mathrm{mg})$ azasetron hydrochloride injectable solution were transferred to $100 \mathrm{~mL}$ polyolefin bags or glass bottles and filled with $0.9 \%$ sodium chloride injection.

Solution 3 (AD20): $4 \mathrm{~mL}(20 \mathrm{mg}$ ) dexamethasone sodium phosphate injectable solution and $2 \mathrm{~mL}(10 \mathrm{mg})$ azasetron hydrochloride injectable solution were transferred to $100 \mathrm{~mL}$ polyolefin bags or glass bottles and filled with $0.9 \%$ sodium chloride injection.

\section{Stability of dexamethasone and azasetron mixture}

Following the American Society of HealthSystem Pharmacists guidelines [45, 46], stability studies were conducted in triplicate for each type of storage condition and container. The physical characteristics of the solutions, such as color, cloudiness, and precipitation were evaluated qualitatively at the time of preparation and at the specified times. Visual examinations were assessed in normal diffuse fluorescent room light with the unaided eye against white and black backgrounds. The $\mathrm{pH}$ values of the mixture were also determined by a PHS-3c pH meter (Leici Instrument Co., Shanghai, China). Furthermore, the concentrations of the drugs were determined at each analysis by the above described HPLC-DAD method. In the concentration analyses, $2 \mathrm{~mL}$ samples were collected from each polyolefin bag or glass bottle and were allowed to reach room temperature before injection into an HPLC system. Samples from each syringe were analyzed in triplicate (total $n=3$ ). The initial concentrations of dexamethasone sodium phosphate and azasetron hydrochloride were defined as $100 \%$, and subsequent sample concentrations for every drug in the mixtures were reported as the percentage of the initial concentration. Stability was defined as the retention of at least $90 \%$ of the initial drug concentration.

\section{CONFLICTS OF INTEREST}

The authors declare no competing financial interests. 


\section{FUNDING}

This work was supported by Hubei Province health and family planning scientific research project of China (No. WJ2015MB215), and Science and Technology Key Program of Shiyan (Number: 16Y66).

\section{REFERENCES}

1. Navari RM, Aapro M. Antiemetic prophylaxis for chemotherapy-induced nausea and vomiting. N Engl J Med. 2016; 374:1356-67. https://doi.org/10.1056/NEJMra1515442.

2. Hesketh PJ. Chemotherapy-induced nausea and vomiting. N Engl J Med. 2008; 358:2482-94. https://doi.org/10.1056/ NEJMra0706547.

3. Sommariva S, Pongiglione B, Tarricone R. Impact of chemotherapy-induced nausea and vomiting on healthrelated quality of life and resource utilization: a systematic review. Crit Rev Oncol Hematol. 2016; 99:13-36. https:// doi.org/10.1016/j.critrevonc.2015.12.001.

4. Janelsins MC, Tejani MA, Kamen C, Peoples AR, Mustian KM, Morrow GR. Current pharmacotherapy for chemotherapy-induced nausea and vomiting in cancer patients. Expert Opin Pharmacother. 2013; 14:757-66. https://doi.org/ 10.1517/14656566.2013.776541.

5. Affronti ML, Schneider SM, Herndon JE 2nd, Schlundt S, Friedman HS. Adherence to antiemetic guidelines in patients with malignant glioma: a quality improvement project to translate evidence into practice. Support Care Cancer. 2014; 22:1897-1905. https://doi.org/10.1007/s00520-014-2136-0.

6. Hesketh PJ, Bohlke K, Lyman GH, Basch E, Chesney M, Clark-Snow RA, Danso MA, Jordan K, Somerfield MR, Kris MG. American Society of Clinical Oncology. Antiemetics: American Society of Clinical Oncology focused guideline update. J Clin Oncol. 2016; 34:381-86. https://doi.org/ 10.1200/JCO.2015.64.3635.

7. National Comprehensive Cancer Network. NCCN Clinical Practice Guidelines in Oncology. Antiemesis, version 2. Fort Washington, PA: Harborside Press; 2015.

8. Basch E, Hesketh PJ, Kris MG, Prestrud AA, Temin S, Lyman GH. Antiemetics: american society of clinical oncology clinical practice guideline update. J Oncol Pract. 2011; 7:395-8. https://doi.org/10.1200/JOP.2011.000397.

9. Yu S, Burke TA, Chan A, Kim HK, Hsieh RK, Hu X, Liang JT, Baños A, Spiteri C, Keefe DM. Antiemetic therapy in Asia Pacific countries for patients receiving moderately and highly emetogenic chemotherapy-a descriptive analysis of practice patterns, antiemetic quality of care, and use of antiemetic guidelines. Support Care Cancer. 2015; 23:273-82. https://doi.org/10.1007/ s00520-014-2372-3.
10. Tsukagoshi S. Pharmacokinetics of azasetron (Serotone), a selective 5-HT 3 receptor antagonist. Gan To Kagaku Ryoho. 1999; 26:1001-08.

11. Hayakawa T, Sato M, Konaka M, Makino A, Hirohata T, Totsu S, Wada Y, Sato H, Inotsume N, Fujita A, Sekine K. Comparison of ramosetron and azasetron for prevention of acute and delayed cisplatin-induced emesis in lung cancer patients. Gan To Kagaku Ryoho. 2006; 33:633-38.

12. Kimura E, Niimi S, Watanabe A, Tanaka T. Clinical effect of two azasetron treatment methods against nausea and vomiting induced by anticancer drugs including CDDP. Gan To Kagaku Ryoho. 1997; 24:855-59.

13. Yun MJ, Kim YH, Kim AR. Comparison of azasetron and ondansetron for preventing postoperative nausea and vomiting in patients undergoing gynecological laparoscopic surgery. Yonsei Med J. 2010; 51:88-92. https://doi. org/10.3349/ymj.2010.51.1.88.

14. Fujii M, Kanke M, Arai Y, Kawai S, Enomoto H, Inaba H, Taguchi T, Tsukuda M. Randomized crossover comparison of azasetron alone and azasetron plus dexamethasone for the prevention of nausea and vomiting by chemotherapy including cisplatin. Gan To Kagaku Ryoho. 1995; 22:1959-67.

15. Lee HY, Song HS. A randomized double-blind, double-dummy, multicenter trial of azasetron versus ondansetron to evaluate efficacy and safety in the prevention of delayed nausea and vomiting induced by chemotherapy. Cancer Res Treat. 2014; 46:19-26. https://doi.org/10.4143/crt.2014.46.1.19.

16. Rosenblatt E, Lev LM, Robinson E. High-dose dexamethasone and high-dose metoclopramide versus high-dose dexamethasone and sulpiridein the management of cisplatin-induced emesis. Oncology. 1988; 45:297-9.

17. Aapro MS, Alberts DS. Dexamethasone as an antiemetic in patients treated with cisplatin. N Engl J Med. 1981; 305:520.

18. Fang BX, Li P, Shi XY, Chen FC, Wang LH. Incompatibilities of lornoxicam with 4 antiemetic medications in polyolefin bags during simulated intravenous administration. Medicine. 2016; 95:e3824. https://doi.org/10.1097/ MD.0000000000003824.

19. Evrard B, Ceccato A, Gaspard O, Delattre L, Delporte JP. Stability of ondansetron hydrochloride and dexamethasone sodium phosphate in $0.9 \%$ sodium chloride and in $5 \%$ dextrose injection. Am J Health-Syst Pharm. 1997; 54:1065-68.

20. McGuire TR, Narducci WA, Fox JL. Compatibility and stability of ondansetron hydrochloride, dexamethasone, and lorazepam in injectable solutions. Am J Hosp Pharm. 1993; 50:1410-14.

21. Chin A, Moon YSK, Chung KC, Gill MA. Stability of granisetron hydrochloride with dexamethasone sodium 
phosphate for 14 days. Am J Health Syst Pharm. 1996; 53:1174-76.

22. Pinguet F, Rouanet P, Martel P, Fabbro M, Salabert D, Astre C. Compatibility and stability of granisetron, dexamethasone, and methylprednisolone in injectable solutions. J Pharm Sci. 1995; 84:267-8. http://dx.doi. org/10.1002/jps.2600840229.

23. Hagan RL, Mallett MS, Fox JL. Stability of ondansetron hydrochloride and dexamethasone sodium phosphate in infusion bags and syringes for 32 days. Am J Health Syst Pharm. 1996; 53:1431-35.

24. Walker SE, Law S. Stability and compatibility of granisetron alone and in combination with dexamethasone in $0.9 \%$ sodium chloride and 5\% dextrose in water solutions. Can J Hosp Pharm. 2002; 55:27-38.

25. Trissel LA, Zhang Y. Compatibility and stability of Aloxi (palonosetron hydrochloride) admixed with dexamethasone sodium phosphate. Int J Pharm Compound. 2004; 5:398-403.

26. Rolin C, Hecq JD, Vanbeckbergen DF, Jamart J, Galanti LM. Stability of ondansetron and dexamethasone infusion upon refrigeration. Ann Pharmacotherapy. 2011; 45:130-131. https://doi.org/10.1345/aph.1P306.

27. Chen FC, Wang LH, Guo J, Shi XY, Fang BX. Simultaneous determination of dexamethasone, ondansetron, granisetron, tropisetron, and azasetron in infusion samples by HPLC with DAD detection. J Anal Methods Chem. 2017; 6749087. https://doi.org/10.1155/2017/6749087.

28. Jordan K, Jahn F, Aapro M. Recent developments in the prevention of chemotherapy-induced nausea and vomiting (CINV): a comprehensive review. Ann Oncol. 2015; 26:1081-90. https://doi.org/10.1093/annonc/mdv138.

29. Wang D, Wang Y, Ma K, Zhang P, Li Z. Study on stability of azasetron hydrochloride injection with infusion solutions under different conditions. China Pharmaceuticals. 2010; 19:20-21. https://doi.org/10.3969/j.issn.1006-4931.2010.24.014.

30. Gupta VD. Chemical stability of dexamethasone sodium phosphate after reconstitution in $0.9 \%$ sodium chloride injection and storage in polypropylene syringes. Int J Pharm Compound. 2002; 6:395-97.

31. Mayron D, Gennaro AR. Stability and compatibility of granisetron hydrochloride in IV solutions and oral liquids and during simulated Y-site injection with selected drugs. Am J Health Syst Pharm. 1996; 53:294-304.

32. Allen LV, Stiles ML, Prince SJ, Sylvestri MF. Stability of cefpirome sulfate in the presence of commonly used intensive care drugs during simulated Y-site injection. Am J Health-Syst Pharm. 1995; 52:2427-33.

33. Watson DG, Lin M, Morton A, Cable CG, Mcarthur DA. Compatibility and stability of dexamethasone sodium phosphate and ketamine hydrochloride subcutaneous infusions in polypropylene syringes. J Pain Symptom Manage. 2005; 30:80-86. https://doi.org/10.1016/j.jpainsymman.2005.01.018.
34. Negro S, Salama A, Sánchez Y, Azuara ML, Barcia E. Compatibility and stability of tramadol and dexamethasone in solution and its use in terminally ill patients. J Clin Pharm Ther. 2007; 32:441-44. https://doi. org/10.1111/j.1365-2710.2007.00839.x.

35. Anderson CR, Halford Z, MacKay M. Stability of diphenhydramine hydrochloride, lorazepam, and dexamethasone sodium phosphate in $0.9 \%$ sodium chloride stored in polypropylene syringes. Int J Pharm Compound. 2015; 19:344-47.

36. Kintzel PE, Zhao T, Wen B, Sun D. Stability of i.v. admixture containing metoclopramide, diphenhydramine hydrochloride, and dexamethasone sodium phosphate in $0.9 \%$ sodium chloride injection. Am J Health Syst Pharm. 2014; 71:2061-65. https://doi.org/10.2146/ajhp130697.

37. Good PD, Schneider JJ, Ravenscroft PJ. The compatibility and stability of midazolam and dexamethasone in infusion solutions. J Pain Symptom Manage. 2004; 27:471-75. https://doi.org/10.1016/j.jpainsymman.2004.02.002.

38. Azuara ML, Sanchez Y, Reyes R, Barcia E. Physical compatibility and in vivo evaluation of drug mixtures for subcutaneous infusion to cancer patients in palliative care. Support Care Cancer. 2002; 10:65-70.

39. Trissel LA, Saenz CA, Ogundele OB, Ingram D, Baker MB. Compatibility of fenoldopam mesylate with other drugs during simulated Y-site administration. Am J Health Syst Pharm. 2003; 60:80-85.

40. Michaels MR, Stauffer GL, Haas DP. Propofol compatibility with other intravenous drug products - two new methods of evaluating IV emulsion compatibility. Ann Pharmacotherapy. 1996; 30:228-232. https://doi. org/10.1177/ 106002809603000303.

41. Wong AH, Law S, Walker SE, Bowles SK. Concentrationdependant compatibility and stability of dexamethasone and midazolam. Can J Hosp Pharm. 2000; 53:24-31.

42. Walker SE, DeAngelis C, Iazzetta J, Eppel JG. Compatibility of dexamethasone sodium phosphate with hydromorphone hydrochloride or diphenhydramine hydrochloride. Am J Hosp Pharm. 1991; 48:2161-66.

43. Kastango ES, Bradshaw BD. USP chapter 797: Establishing a practice standard for compounding sterile preparations in pharmacy. Am J Health Syst Pharm. 2004; 61:1928-38.

44. Trissel LA. The new national standard for sterile preparation. Hosp Pharm. 2004; 39:900-904.

45. American Society of Health System Pharmacists. ASHP guidelines on quality assurance for pharmacyprepared sterile products. Am J Health Syst Pharm. 2000; 57:1150-69.

46. Thompson CA. USP publishes enforceable chapter on sterile compounding. Am J Health Syst Pharm. 2003; 60:1814, 1817-8, 1822. 